University of Windsor

Scholarship at UWindsor

2011

\title{
Older Athletes' Perceived Benefits of Competition
}

Rylee A. Dionigi

Joseph Baker

Sean Horton

University of Windsor

Follow this and additional works at: https://scholar.uwindsor.ca/humankineticspub

Part of the Kinesiology Commons, and the Sports Sciences Commons

\section{Recommended Citation}

Dionigi, Rylee A.; Baker, Joseph; and Horton, Sean. (2011). Older Athletes' Perceived Benefits of Competition. The International Journal of Sport and Society, 2 (2), 17-28.

https://scholar.uwindsor.ca/humankineticspub/5

This Article is brought to you for free and open access by the Faculty of Human Kinetics at Scholarship at UWindsor. It has been accepted for inclusion in Human Kinetics Publications by an authorized administrator of Scholarship at UWindsor. For more information, please contact scholarship@uwindsor.ca. 


\title{
Older Athletes' Perceived Benefits of Competition
}

\author{
Rylee A. Dionigi, Charles Sturt University, NSW, Australia \\ Joseph Baker, York University, Ontario, Canada \\ Sean Horton, University of Windsor, Ontario, Canada
}

\begin{abstract}
Intense sport competition is typically associated with young people. Also, much of the literature on exercise for older adults focuses on benefits derived from regular physical activity, such as walking, dancing and fitness classes, and suggests that one should avoid extremely strenuous exercise. The rising phenomenon of older people competing in sport presents a challenge to these assumptions. In 2009, approximately 28,000 athletes from 95 countries gathered in Sydney, Australia to compete across 28 different sports at the World Masters Games. We interviewed 44 competitors (23 females, 21 males; aged 56-90 years; $M=72$ ) about what they gained from competing in sport that extended beyond non-competitive physical activity outcomes. Five key themes emerged from the data. The first theme, "I like a challenge", depicts Masters sport as an ideal context to test one's abilities. In particular, lifelong athletes (or those who had returned to sport after a long break) enjoyed the satisfaction of knowing they "can still do it"! On the other hand, Masters competitions provide space for older people to begin sport in later life, as the second theme highlights, "I discovered that at this age group I could win things"! Theme three, "I'm more motivated to work harder", describes how regular competitions provided goals for participants which structured their training. Also, the act of competing brought out their best performances. The fourth theme, "You know where you stand", shows how participants liked that competition enabled them to compare themselves with others of their own age cohort. The final theme, "Travel" and "companionship", explains how the organized, competitive structure of Masters sport and its club system allowed for regular travel, the establishment of ongoing friendships and weekly social interaction. Our data suggest that sport provides unique benefits to participants above and beyond those gained from general physical activity.
\end{abstract}

Keywords: Sport, Masters Games, Older Adults, Qualitative Research

\section{Introduction and Background}

TN THE CONTEXT of aging populations around the world, improving patterns of physical activity involvement in older age groups is an increasingly important concern in industrialized societies. Although most public health advocates focus on the robust relationship between involvement in physical activity and prevention of most chronic diseases (for a detailed review see Sallis \& Owen, 1999), research also indicates that physical activity and regular exercise have similar positive effects on the maintenance of cognitive and physical functioning both in clinical (e.g., Feinglass, Thompson, He, Witt, Chang, \& Baker, 2005) and non-clinical (e.g., Visser et al., 2005) populations. Unfortunately, national population data continue to emphasize the association between advancing age and decreasing physical activity levels. However, one type of physical activity involvement, competitive sport, has increased in popularity over the past two decades (Weir, Baker, \& Horton, 2010)

The International Journal of Sport and Society

Volume 2, Issue 2, 2011, http://sportandsociety.com/journal/, ISSN 2152-7857

C Common Ground, Rylee A. Dionigi, Joseph Baker, Sean Horton, All Rights Reserved, Permissions:

cg-support@commongroundpublishing.com 
and some researchers, particularly sports scientists, have strongly advocated it as an optimal type of activity for older people (e.g., Hawkins, Wiswell, \& Marcell, 2003).

Although it is difficult to identify the specific 'birthdate' of Masters sport, it is generally accepted that its origins were in the United States in the sport of athletics during the 1960s (Weir et al., 2010). The first Masters US Track and Field Championship was held in 1968 with the first World Masters Track and Field Championship in Toronto in 1975. Although starting in athletics, Masters (or Veterans) sport continued to grow in popularity throughout the 1970s and 1980s. By the 1990s, many sporting bodies reported that, in terms of participant numbers, the Masters level was the fastest growing area in their sport (see for example Burns, 1992) and remains one of the fastest expanding sectors of sport (e.g., Dionigi, 2008; Jokl, Sethi, \& Cooper, 2004). At the international level, the number of participants competing at the World Masters Games has increased almost four-fold since the inaugural World Masters event in 1985 in Toronto, Canada (Weir et al., 2010). At the Sydney 2009 World Masters Games approximately 28,000 athletes representing 95 countries participated in 28 different sports. There are 50,000 athletes expected at the next World Masters Games in Turin, Italy in August, 2013 (http://www.torino2013.org/).

Age (not ability) is the qualifier for participation in Masters sport, with competitors usually ranging in age from 30 years to over 90 years (Weir et al., 2010). In this context, it is accepted that an athlete's performance will decline with advancing age (Tulle, 2007; 2008). Therefore, Masters sport allows older people to compete against others within a similar age range (typically $5-10$ years) in a variety of sports at organized local, national or international competitions on a regular basis (Dionigi, 2008). Nevertheless, intense sport competition is typically associated with young people. Sport is often emphasized as an ideal vehicle for the positive development, health and well-being of youth, such as helping participants build competency and character, develop friendships, and contribute to society (see Holt, 2008). More recently, however, researchers have begun exploring competitive sport as an optimal activity for maintenance (and improvement) of health, functioning and identity management among older adults on the basis that the advantages of sport participation apply across the lifespan and extend beyond the benefits of regular exercise (see Baker, Fraser-Thomas, Dionigi, \& Horton, 2010 for a review).

We know very little about the value of sport participation on health and functioning of older adults, largely due to the newness of this phenomenon and the relative paucity of older athletes (at least when compared to the majority of people in their age cohort). Furthermore, much of the literature on exercise for older adults focuses on benefits derived from noncompetitive activities of low-to-moderate intensity such as walking, dancing and fitness classes, suggesting that one should avoid extremely strenuous exercise. Indeed, the position advocated by Dr. J.W. Bell at the conference of the American Medical Association over 100 years ago that older adults should "...undertake no violent exercise... If they are allowed any outdoor sport at all they should take gentle exercise involving only slow steady movements" (Bell, 1899, as cited in Vertinsky, 1991, p. 77) continues to have a large degree of influence, despite a clear lack of evidence supporting its validity. For example, Grant (2001, p. 785) found that older New Zealand Masters athletes had to negotiate attitudes such as "at your age you shouldn't be doing this" when deciding to begin or continue sports participation in later life.

Conversely, some researchers (Hawkins et al., 2003) argue that older (i.e., Masters) athletes are ideal models of 'successful aging' because they typically report greater levels of health 
and functioning than their age-matched sedentary contemporaries. However, much of the literature on Masters sport and older athletes has focused on physiological and psychological health outcomes associated with sustained involvement in regular physical activity (Baker, Horton, \& Weir, 2010). Much less research has focused on the meaning competitive sports participation holds in the lives of older people and how sport has the potential for benefits above and beyond those gained from general physical activity.

Therefore, the purpose of this qualitative study was to determine what a group of World Masters Games competitors gained from competing in sport that extended beyond noncompetitive physical activity outcomes. The findings may inform our understanding of personal growth and identity development among older athletes as well as describe the psychosocial processes underpinning continued involvement in an activity with considerable health-preserving qualities. This research may also provide insight into cultural factors and equity issues affecting sports participation in later life.

\section{Method}

\section{Data Collection}

Data for this analysis come from a larger study of Masters athlete competition at the Sydney 2009 World Masters Games (WMG; Dionigi, Horton, \& Baker, 2010). These games were held over 10 days involving 28 sports with approximately 28,000 competitors from 95 countries participating in this event. We conducted 44 onsite interviews (averaging 30 minutes each in length) with 44 athletes competing in the games (aged 56-90 years; $M=72$ years). Participants for this research were theoretically sampled (Patton, 2002) according to age (over 55 years), gender (both men and women), sport (a variety of events) and country (English-speaking). Study participants were from Australia $(n=24)$, Canada $(n=9)$, the United States of America $(n=6)$ and New Zealand $(n=5)$. They were typically white and middleclass, which reflects the demographic of the majority of participants at Masters events. The sample competed in swimming $(n=21)$, athletics/track and field $(n=9)$, squash $(n=4)$, orienteering $(n=3)$, weightlifting $(n=3)$, tennis $(n=2)$, badminton $(n=2)$ or cycling $(n=1)$. Fortyfive percent of participants began competing at the Masters level (when they were over 50 years of age) while 55 percent of the group were comprised of life-long 'continuers' of sport or 're-starters' of sport (i.e., those who had returned to sport after raising their children and/or when they retired from employment).

All participants provided informed consent and pseudonyms have been used in the analyses below to conceal the identity of the participants. We asked participants open-ended questions about what outcomes they experience from competing. More specifically, we asked them: "What are the key reasons why you compete in sport? (i.e., What is it about competing that attracts you/maintains your interest?) and "What do you get out of competing in sport?" (i.e., What do you get from competition that you do not get from participating in other forms of non-competitive exercise or general physical activity?).

\section{Data Analysis}

The interview data were analyzed using codes and the constant comparison method (Strauss $\&$ Corbin, 1998). Initially, each transcript was read and coded individually according to the 
foci questions outlined above. The codes were then compared across the entire data set until raw data themes were developed to represent the most common findings among the participant sample. This process of cross-case analysis allowed the data to be grouped together under these initial (descriptive) theme categories (Miles \& Huberman, 1994). The next stage of analysis involved developing higher order themes (more refined concepts) from these raw data themes by linking similar themes together or dropping irrelevant themes (Van Manen, 1998). The purpose of this stage was to determine the most common themes representing the perceived benefits of competition. In-vivo codes (i.e., phrases taken from participants' direct quotes) have been used as theme titles (Strauss \& Corbin, 1998). Five key themes emerged from data analysis: (1) "I like a challenge"; (2) "I discovered that at this age group I could win things"; (3) "I'm more motivated to work harder"; (4) "You know where you stand"; (5) "Travel" and "companionship". These themes were common across age, gender, and nationality, but varied in terms of sporting background (i.e., beginners compared to lifelong athletes or re-starters).

\section{Results}

\section{"I Like a Challenge"}

The first theme, which we have summarized as "I like a challenge", depicts Masters sport as an ideal context to test one's abilities. In particular, lifelong athletes (or those who had returned to sport after a long break) enjoyed the satisfaction of knowing they "can still do it"! This theme was primarily about self-comparison and pushing the body to its limit. For example, Walter, an 80-year-old Australian swimmer who began competitive swimming at 20 years of age, explained:

I always enjoy a challenge. My wife says I'm a competitive animal. And I enjoy a challenge to better myself either to beat a time, or to break a record, or to do a personal best. And I'm always looking to do that and it's very encouraging.

Darren, age 61, a Canadian swimmer who returned to sport at the Masters level in his midforties agreed, "I think it's the challenge. You are always striving to either get a personal best or to lose as little as you can...I don't have to come first although it is nice." Glenda, a 78-year-old Canadian who has been competing in Masters swimming for 20 years elaborated:

I like a challenge... pushing yourself to a newer level is good too... we're always doing times in swimming in our workouts, so you measure yourself by how you're doing and I think it's important to do that. I couldn't just swim for leisure... and not get anything out of it.

Likewise, Donna, age 66, a long-distance runner from Australia said:

I've been competing a long time, since about $1982 \ldots$ I'm not one who would run just to keep fit. I like the competition, the idea of bettering myself and beating someone else... It keeps me motivated and keeps me going and it does of course keep me fit, but that's a side benefit. 
Rick, a 74-year-old Australian athlete, who has been competing in track and field since the age of 18, also stressed that the enjoyment of pushing oneself in a competitive context was more important than fitness or health benefits:

It really is a personal thing that you're chasing... but at the same time there is this competition. You do want to win, don't let me give you the impression I don't want to win, you bet I do, but it's not the reason for doing it. The reason for doing it is because I enjoy the physical side of it and just against yourself all the time... I don't do it for health reasons, I'd stress that. I don't do it because I think I'm going to live longer, or I'm going to live better, or anything like that. I do it because I enjoy it.

The notion of being able to compete and still enjoy sports competition was strongly communicated through the voices of lifelong or returning athletes. For instance, Lucy (age 69 from New Zealand), a representative (elite) netball player in her youth who progressed to Masters badminton at age 33, said:

I just enjoy it because competing with myself, even though I'm competing against others, but I play for myself...It just gives you a marvelous feeling that you can still compete at this age level and I think, that's what we always say as long as the body tells us that we can still participate, yeah I'll do it...

On the other hand, Masters competitions provided space for older people to begin sports participation in later life and experience winning or set personal best performances for the first time, as highlighted in the second theme.

\section{"I Discovered that at this Age Group I Could win Things!"}

Forty-five percent of study participants indicated that they began competing in sport at the Masters level when they were over 50 years of age. Masters sport offers space for people who have never competed in sport to commence this activity in later life, provided they have the means, ability, opportunity and desire to do so. The Masters sport context caters to and accepts age-related declines in sport performance by structuring competitions in age categories. Participants compete in five year age groups for individual sports (e.g., 55-59 or 60-64) and ten year age-bands for team sports. At international competitions, like the World Masters Games, participants have the opportunity to set world records for their age group in certain events.

Therefore, people who have never been sports participants have the chance to become competitive athletes in later life and perhaps experience success in this context for the first time. For example, Marlene, a 66-year-old woman from New Zealand, took up Masters swimming at age 59 and she is not looking back:

Well one thing was that as a younger person I was never successful. I was never really good at something and when I discovered that at this age group I could win things and get recognition from it, it just really spurred me on and we've got a lot of medals between the two of us [herself and her husband]. We've got about 54 medals. Which we hang up in the cupboard to inspire the grandchildren... I never, ever considered myself to 
be a competitive person... but once I had got something it really kicked something awake in me and now I'm out there to win.

Similarly, 86-year-old Barney from the U.S.A, who called himself "a late bloomer" because he started competing in Masters athletics throwing events at age 75, said that competing allows him to enjoy "being better than somebody else. Oh yes, it's nice to be king of the hill." He was wearing his medals proudly around his neck when he was interviewed.

For other late starters to competition, Masters sport provided a context to establish personal best (PB) performances. For example, Masters swimming allowed Matt, a 69-year-old Australian, to determine his personal best times because he had no past performance standards of which to compare his current race times. He explained, “... because I've never really been a good sportsman, certainly never been a good swimmer, I have the opportunity of still doing PBs right?" These findings demonstrate that the desire for performance enhancement and the value placed on winning and recognition in sport does not necessarily diminish with advancing age.

\section{"I'm more Motivated to Work Harder"}

This theme describes how regular competitions provided goals for participants which structured their training and gave it a purpose. As Mark explained, "Well, right now the key reason is that competing gives me a target to head for... by knowing I'm going to be competing, I'm then motivated to go out and do the workouts, and stay in shape and stay healthy" (age 56, Canadian swimmer). Participants described the rigorous training schedules they undertook to maintain their health and fitness and perform at their peak during major competitions. For example, 90-year-old Olivia, a track and field athlete from Canada, said:

... the main idea is for me to keep healthy, strong, prior to the competition so that I can maintain and do well during the competition... I think winning is important and I think that's what I focus on because I always check to see what the record is to see if I can meet it or beat it. And that keeps me going and travelling.

Also, the act of competing brought out their best performances and participants said it made them try harder than they would in a non-competitive activity. Bill, a 61-year-old Australian tennis player elaborated:

I just find that you try that little bit harder when it's competition. You can play social all you like but when it's competition it just brings out the best in you I find and you do know it after you've played in a competition... your body does ache so you know you're putting in that extra bit of effort. So it's good and I enjoy the competition.

Some participants were motivated to improve their own performance standards. For instance, Betty said:

... you're sort of competing with yourself all the time and when you do get older, you just can't meet some of those times that you used to be able to do, so you try to get close to those ones... I'm more motivated to work harder. (64-year-old, Canadian swimmer) 
Other participants were motivated to train, and keep fit and healthy, for social comparison. This latter finding was common among participants, regardless of age, gender, nationality or when they began competing; therefore, it is elaborated in the next theme.

\section{"You know where you Stand"}

This theme shows how participants liked that competition enabled them to compare themselves with others of their own age cohort. For example, Donna from Australia, age 66, became a long-distance runner at the age of 39. She said:

It's just that I've got a competitive nature I suppose and I just like improving and the fact that I can beat someone else of my age. I find it's very stimulating and interesting...

Similarly, 78-year-old Glenda, who became a Canadian Masters swimmer at age 58 stated:

I think training isn't enough. You have to show what you get from your training. So by going into competition you know where you stand. Otherwise you... never get any better...

This theme also focuses on the perceived importance of opportunities for social comparison, in regard to sporting ability and factors associated with aging. As Victor explained:

... it's nice to get a measure of where you stand compared to others. Until you do compete, you are sort of on a little island, but because we are here [at the WMG], the world's the limit. (a 71-year-old Canadian who has played squash for 50 years)

Likewise, Daniel, who began competitive squash at the age of 13, commented:

[I enjoy] the competition itself because you are going to be playing with not just players of your own level, but you are going to be playing players of a higher level and keener competition. (age 78, Canada)

Therefore, these above two athletes could make comparisons based on squash skills and ability.

Some participants compared themselves to 'other' older people in general when describing the benefits of competitive sport. For instance, Judy, age 74, who has competed in athletics since she was 12 years old (but had a break while raising children and then returned to Masters track and field in later life) explained:

I like doing what I'm doing in athletics and I'm able to do it... it keeps me healthy, keeps me alert, keeps the old mind ticking over which is pretty important because I go to nursing homes to see my ex mother-in-law and some of the people in there are much younger than me and they're just sitting there doing nothing, and it's sad to see all that. It really is.

In stark contrast to the 'nursing home' scene described above, the participants in this study were travelling and socializing through competitive sport. 


\section{"Travel" and "Companionship"}

The data in this theme explains how the organized, competitive structure of Masters sport and its club system allowed for regular travel, the establishment of ongoing friendships and weekly social interaction. To Betty, the benefit of competitive sport is that, "... it motivates you to get out and socialize and have fun with other adults that enjoy keeping physically fit" (age 64, Canadian swimmer). Heidi, a 76-year-old Australian track and field athlete elaborated:

Oh just the companionship with all these great girls that I see mostly you know, my own club at home and then down here when we get into another [track and field] meet where I can meet up with all the interstaters and even some of the overseas people that I've met before and make friends with some of the new ones. It's great. Just the company and we encourage everyone, you know.

Similar stories were told by men and women from swimming and squash clubs. For example, Martha, an 82-year-old Australian swimmer said:

Just love it, always have loved swimming... the people are all interested in swimming and one of the ladies I beat yesterday, you know, came up and gave me a hug and said "congratulations!"

Likewise, Jack (age 64, Australian) explained why he loves to compete:

Just the camaraderie of the Masters where you meet all the different sorts of people, like today you meet everybody from different parts of the world... you can talk about swimming, which is the main subject.

The social aspect and friendships formed also encouraged ongoing participation, as Tom explained:

I enjoy the sport, the activity and also trying to keep in good health and especially in squash you meet very, very nice social people, very enjoyable and making lasting friends through the sport... when you are with a group of guys, you get attached to them, you meet those guys almost every week, which is more than what you spend with friends... You have supper and a drink and you get to know those people... and that creates a very good bond there and when you have got a group of people like that, you tend to play year after year to keep on with the same enjoyable group. (age 81, Australian)

\section{Discussion and Implications}

Our data suggest that competitive sport provides unique benefits to participants above and beyond those gained from general physical activity. Generally, the themes highlighted by the competitors reflected the unique context of Masters sport for older people. Two themes ( 2 and 5 ) dealt with the opportunities provided by Masters sport such as being able to participate in competitive sport at an older age, as well as opportunities for travel as a result of Masters competition, the establishment of ongoing friendships and regular social interaction. 
Theme 2 highlighted that Masters sport allowed some participants to become athletes in later life. In this sense, older people were establishing a new or alternative identity as a winner, a sports champion and a highly physically active person. Similar findings have emerged from studies on older Australian and New Zealand Masters athletes where it was argued that participation in sport in later life can be a personally empowering experience (Dionigi, 2002; Grant, 2001).

Theme 5 described how participants were leading a highly leisured, active and social lifestyle. Older athletes appear to be a somewhat select or privileged group who possess the time, ability, health, desire and disposable income to regularly train and travel to sites of competition (Dionigi, 2008; Grant, 2001; Tulle, 2007). Indeed, not all older people are in this position and those who cannot or do not want to participate in sport should not feel pressured to 'follow their lead'. Issues of ability, access and equity associated with continued participation in competitive sport have been raised by Dionigi and O'Flynn (2007) who warned us of the potential consequences of positioning older athletes as 'successful agers' and sports participation as a realistic option for all older people. For instance, while sport is promoted as a means to achieving holistic health in later life, its advocates (such as the World Health Organization and its 'sport for all' philosophy) imply that sports participation is the civic duty of a responsible older citizen (Dionigi, 2011). Much more research is needed on older people who do not compete in sport to counter-balance the viewpoints and experiences presented in the current study. Only a couple of small studies have attempted to understand feelings towards sport and Masters athletes from the perspective of less physically active older people. Both Horton, Baker, Côté and Deakin (2008) and Dionigi, Horton, Bellamy and Baker (2009) have reported that while some older people saw elite Masters athletes as inspiring, others, in direct contrast, found them intimidating, and still others said they had no effect at all on their personal health practices.

Another two themes ( 1 and 4) dealt with 'liking a personal challenge' and 'finding out where one stands', which generally reflected a desire to establish the limits of current levels of functioning. The unique demands of competitive sport with its requirement that competitors push to the limits of their capabilities may be an optimal venue for this 'testing the limits' philosophy. Although it is possible that regular exercisers also get 'up to date' information regarding changes in physical functioning, it is likely that participation in competitive sport provides a superior indicator of what the older person is capable of due to competition against likeminded peers in a controlled environment with objective performance feedback. In addition to the personal performance feedback individuals receive they also get feedback about their level of functioning relative to the highest functioning members of their peer group (in some cases compared to the highest performing older adults in the world), which may have important effects on factors such as an individual's motivation for continued participation or their optimism for the aging process in general (Horton, 2010).

Alongside their stories of enjoyment and empowerment, many of the participants went to some lengths to emphasize Masters sport as 'serious competition'. On the one hand, in Western cultures sport is understood as highly competitive, performance-oriented and professionalized with a history of being organized for and promoted to young people, males in particular (Cashman, 1995). On the other hand, proponents emphasize sport as a context for joy, inclusion, fair play, co-operation, pleasurable movement experiences and personal growth (Coakley, 2007). The latter 'pleasure and participation' view is often associated with youth sport and so-called alternative sports, such as disability sport, Gay Games and the 
Masters Games (Coakley). It is clear from our study (see also Dionigi et al., 2010) that participants invest in both the performance enhancement model and the participation model of sport. The participants valued and enjoyed the outcomes of competition (such as winning, recognition, medals, world records) and the processes of participation (such as self-improvement, fair play, socializing, pleasure in movement). Further research is needed to determine whether Masters sport represents an 'ideal' model of competitive sports participation.

The other theme (3) reflected the increased motivation athletes get from regular competition and how this provided clear goals for performance improvement or maintenance. These findings echo Dionigi's (2006) review of the literature on the motives and perceived benefits of older people involved in competitive (rather than recreational) sport that seems to suggest Masters athletes may have a motivation profile that promotes continued involvement in physical activity and exercise. However, motivation researchers (e.g., Young \& Medic, 2011) distinguish between 'wanting' to do something (functional commitment) and 'having' to do something (obligatory commitment) suggesting that continued examination of the motivation to maintain or increase training is necessary. On the one hand, regular exercise likely plays an important role in reducing age-related morbidity and maximizing physical and cognitive functioning. On the other hand, socio-cultural pressure, such as health promotion guidelines emphasizing regular physical activity may promote a sense of obligation in older adults rather than more functional forms of commitment. The long-term consequences of the latter, such as how feelings of 'having to exercise' interact with age-related existential issues (e.g., bodily limitations, ill health and death), have not yet been explored. Therefore, although many benefits are derived from sports competition and the promotion of sport for older people is a laudable goal, there is a need to proceed with caution given the different personal, social, cultural, economic and historical factors affecting sports participation in later life.

\section{Acknowledgements}

The lead author would like to acknowledge the support provided by Charles Sturt University's Centre for Inland Health, Research Centre Fellowship. The research collaboration resulting in this work was also supported by Charles Sturt University's, Faculty of Education, Research Development Fund. The authors would like to thank Communities NSW and the Sydney World Masters Games Organising Committee for allowing us to conduct this research at the Sydney 2009 World Masters Games. The views expressed in this publication are the views of the authors and do not necessarily represent the views of the participants in this research.

\section{References}

Baker, J., Fraser-Thomas, J., Dionigi, R., \& Horton, S. (2010). Sport participation and positive development in older persons. European Review of Aging and Physical Activity, 7, 3-12.

Baker, J., Horton, S. \& Weir, P. (Eds.) (2010). The Masters athlete: Understanding the role of sport and exercise in optimizing aging.. London UK: Routledge.

Burns, R. (1992). Play on. The report of the Masters sport project on mature aged sport in Australia. Canberra: Australian Sports Commission.

Cashman, R. (1995). Paradise of sport: The rise of organised sport in Australia. Oxford: Oxford University Press Australia.

Coakley, J. (2007). Sports in society: Issues and controversies (9 $9^{\text {th }}$ ed.). New York: McGraw-Hill. 
Dionigi, R. A. (2002). Leisure and identity management in later life: Understanding competitive sport participation among older adults. World Leisure Jou rnal, 44, 4-15.

Dionigi, R. A. (2006). Competitive sport and aging: The need for qualitative sociological research. Journal of Aging and Physical Activity, 14(4): 365-379.

Dionigi, R. A. (2008). Competing for life: Older people, sport and ageing. Saarbrüecken, Germany: VDM Verlag Dr. Müller.

Dionigi, R. A. (2011). Older athletes: Resisting and reinforcing discourses of sport and aging. In S. Spickard Prettyman \& B. Lampman (Eds.). Learning culture through sports: Perspectives on society and organized sports (pp. 260-278). Lanham, MD: Rowman \& Littlefield Education.

Dionigi, R. A., Horton, S. \& Baker J. (2010). Seniors in sport: The experiences and practices of older World Masters Games competitors, International Journal of Sport and Society, 1, 55-68.

Dionigi, R.A., Horton, S., Bellamy, J., \& Baker, J. (2009). Promoting healthy aging: role models and exercise behaviour of seniors. Paper presented at the American Psychological Association Annual Conference, Toronto, Canada.

Dionigi, R. A. \& O'Flynn, G. (2007). Performance discourses and old age: What does it mean to be an older athlete? Sociology of Sport Journal. 24, 359-377.

Feinglass, J., Thompson, J. A., He, X. Z., Witt, W., Chang, R. W. \& Baker, D. W. (2005). Effect of physical activity on functional status among older middle-age adults with arthritis. Arthritis and Rheumatism, 53, 879-885.

Grant, B. C. (2001). "You're never too old": Beliefs about physical activity and playing sport in later life. Ageing and Society, 21(6), 777-798.

Hawkins, S.A., Wiswell, R.A., \& Marcell, T.J. (2003). Exercise and the master athlete: A model of successful aging? Journal of Gerontology: Medical Sciences, 58A, 1009-1011.

Holt, N. (2008). Positive youth development through sport. London UK: Routledge.

Horton, S. (2010). Masters athletes as role models? Combating stereotypes of aging. In J. Baker, S. Horton, \& P. Weir. (Eds.), Masters athletes: Understanding the role of exercise in optimizing aging. (pp 122-136). London UK: Routledge

Horton, S., Baker, J., Côté, J., \& Deakin, J. (2008). Understanding seniors' perceptions and stereotypes of aging. Educational Gerontology, 34, 997-1017.

Jokl, P., Sethi, P.M. \& Cooper, A.J. (2004). Masters' performance in the New York City Marathon: 1983-1999. British Journal of Sports Medicine, 38, 408-412.

Miles, M. B., \& Huberman, A. M. (1994). Qualitative data analysis: An expanded source book. London: Sage Publications.

Patton, M.Q. (2002). Qualitative evaluation and research methods. ( ${ }^{\text {rd }}$ Ed.). London: Sage Publications Ltd.

Sallis, J. F., \& N. Owen, N. (1999). Physical activity and behavioral medicine. Thousand Oaks, CA: Sage Publications.

Strauss, A., \& Corbin, J. (1998). Basics of qualitative research: Techniques and procedures for developing grounded theory (2nd ed.). Thousand Oaks, CA: Sage Publications.

Tulle, E. (2007). Running to run: Embodiment, structure and agency amongst Veteran elite runners, Sociology, 41(2), 329-346.

Tulle, E. (2008). Acting your age? Sports science and the ageing body, Journal of Aging Studies, 22, 340- 347.Van Manen, M. (1998). Researching lived experience: Human science for an action sensitive pedagogy (2nd ed.). London, ON: Althouse Press.

Vertinsky, P. (1991). Old age, gender and physical activity: The biomedicalization of aging. Journal of Sport History, 18, 64-80.

Visser, M., Simonsick, E. M., Colbert, L. H., Brach, J., Rubin, S. M., Kritchevsky, S. B., et al. (2005). Type and intensity of activity and risk of mobility limitation: the mediating role of muscle parameters. Journal of the American Geriatric Society, 53, 762-770. 
Weir, P., Baker, J., \& Horton, S. (2010). The emergence of Masters sport: participatory trends and historical developments. In J. Baker, S. Horton, \& P. Weir. (Eds.), The Masters athlete: Understanding the role of sport and exercise in optimizing aging. (pp 7-14). London UK: Routledge.

Young, B. W. \& Medic, N. (2011). Examining social influences on the sport commitment of Masters swimmers. Psychology of Sport and Exercise, 12(2), 168-175.

\section{About the Authors}

Dr. Rylee A. Dionigi

Rylee Dionigi is Associate Head of the School of Human Movement Studies at Charles Sturt University, Australia. She has published in the fields of sport sociology, ageing and physical activity, exercise psychology and leisure studies. Dr. Dionigi has expertise in qualitative research methods and extensive knowledge on 'the older athlete'. Her book, Competing for life: Older people, sport and ageing (2008), is the first published research monograph to present extensive empirical qualitative data on the personal and cultural meanings of competitive sports participation in later life.

\section{Dr. Joseph Baker}

Joseph Baker is an Associate Professor of Kinesiology and Health Science at York University, Canada. Dr. Baker has an established and wide-ranging research track record on examining factors associated with physical activity and optimal development across the lifespan. He has recently published a number of papers on the maintenance of physical and cognitive capacities with age that have received a significant amount of attention from both the scholarly community and the popular press. He has expertise in quantitative and qualitative research methods.

\section{Dr. Sean Horton}

Sean Horton is an Assistant Professor of Kinesiology at the University of Windsor, Canada. Dr. Horton has an established knowledge of the impact of stereotypes on the health and performance of seniors. He has expertise in quantitative, qualitative and meta-analytic techniques. Dr Horton takes a multi-disciplinary approach to the study of seniors and physical activity which has resulted in numerous journal publications. 
Copyright of International Journal of Sport \& Society is the property of Common Ground Publishing and its content may not be copied or emailed to multiple sites or posted to a listserv without the copyright holder's express written permission. However, users may print, download, or email articles for individual use. 